\title{
Abundância, sobrevivência e crescimento de plântulas de Ipomoea pes-caprae (L.) R. Br. (Convolvulaceae) na Ilha de Santa Catarina, SC, Brasil
}

\author{
Tânia Tarabini Castellani1 ${ }^{1,3}$ e Flávio Antonio Maës dos Santos²
}

\author{
Recebido em 28/09/2005. Aceito em 18/05/2006
}

\begin{abstract}
RESUMO - (Abundância, sobrevivência e crescimento de plântulas de Ipomoea pes-caprae (L.) R. Br. (Convolvulaceae) na Ilha de Santa Catarina, SC, Brasil). Plântulas de Ipomoea pes-caprae ocorreram em nove das dez praias estudadas na Ilha de Santa Catarina, SC, e em 21 das 30 manchas monitoradas, não ocorrendo na praia de menor extensão. Suas densidades variaram de 0 a 5,2 plântulas m², sendo estas diferenças em parte explicadas pela densidade de sementes viáveis no solo. A sobrevivência de plântulas foi baixa, $0,6 \%$, se considerarmos as 2.823 plântulas acompanhadas em três anos. Os principais fatores de morte foram a erosão e o soterramento marinhos. Nenhuma plântula sobreviveu no setor de alta praia $(\mathrm{n}=2684)$. Houve sobrevivência em duna frontal, sob mancha estabelecida $(0,8 \%, \mathrm{n}=119)$, em área em recolonização, onde os indivíduos foram parcialmente removidos $(80,0 \%, \mathrm{n}=20)$ e em áreas recentes, reconstruídas após a remoção total da população (quatro plântulas observadas) onde atingiram o maior desenvolvimento. Experimentos mostraram que plântulas com um mês de idade não toleram soterramentos de $10 \mathrm{~cm}$. Com $5 \mathrm{~cm}, 50,0 \%$ sobrevive, mas mostra menor número de folhas, menor biomassa e menor alocação à formação de raízes e caule. Todas as plântulas de Ipomoea pes-caprae estabelecidas, o fizeram em período sem erosão costeira, sendo esta duração da estabilidade do hábitat um fator chave para a regeneração de Ipomoea pes-caprae.
\end{abstract}

Palavras-chave: dunas costeiras, sobrevivência de plântulas, crescimento de plântulas, erosão, soterramento

\begin{abstract}
Abundance, survival and growth of Ipomoea pes-caprae (L.) R. Br. (Convolvulaceae) seedlings on Santa Catarina Island, Santa Catarina State, Brazil). Seedlings of Ipomoea pes-caprae occurred on nine of the beaches studied $(\mathrm{n}=10)$ at Santa Catarina Island, (State of Santa Catarina) and in 21 monitored patches $(n=30)$; it did not occur at the smallest beach. Seedling densities varied from 0 to $5.2 \mathrm{~m}^{2}$, and these differences are in part explained by viable seed bank densities. Seedling survival was low $(0.6 \%)$ considering the 2823 plants monitored over three years. The main causes of death were wave erosion and burial. No seedlings survived at the beach zone $(\mathrm{n}=2684)$. Seedlings survived in the fore dune, in patches of Ipomoea pes-caprae $(0.8 \%, \mathrm{n}=119)$, in recolonization areas where Ipomoea pes-caprae was partially removed $(80.0 \%, \mathrm{n}=20)$ and in recent dune areas, which were reconstructed after intense wave erosion (four seedlings observed). Seedling growth was greatest at the latter. Experiments showed that one-month-old seedlings did not tolerate burial in $10 \mathrm{~cm}$ of sand. When buried by $5 \mathrm{~cm}$ of sand, $50.0 \%$ of the seedlings survived, but these had fewer leaves, lower biomass and lower allocation to root and shoot development. All established seedlings of Ipomoea pes-caprae were recruited in a period without wave erosion; habitat stability was a key factor in Ipomoea pes-caprae regeneration.
\end{abstract}

Key words: coastal dunes, seedling survival, seedling growth, erosion, burial

\section{Introdução}

Diferentes estratégias de colonização e estabelecimento são atribuídas às espécies construtoras de dunas. Enquanto algumas se estabelecem de botões germinativos dormentes em fragmentos de ramos e por altas taxas de crescimento vegetativo (Maun 1985; Bernardi et al. 1987; Bernardi \& Seeliger 1989), outras são dependentes de sementes para colonizar e se regenerar em uma população local (Johnson 1985; Maun 1985).
Os principais fatores que limitam o estabelecimento de plântulas em dunas são a disponibilidade de umidade, a cobertura vegetal e o soterramento. A umidade interfere na germinação, emergência e sobrevivência das plântulas, podendo restringir o recrutamento a anos de maior pluviosidade (Meijden \& Waals-Kooi 1979; Boorman \& Fuller 1984; Maun 1985; 1994; De Jong \& Klinkhamer 1988; Castellani et al. 1995; 2001). Quanto à cobertura vegetal, algumas espécies não germinam sob vegetação densa, dependendo de pequenas clareiras para o estabelecimento inicial

\footnotetext{
1 Universidade Federal de Santa Catarina, Centro de Ciências Biológicas, Departamento de Ecologia e Zoologia, C. Postal 476, 88040-900 Florianópolis, SC, Brasil (Bolsa PICD/Capes, Pós-Graduação em Ecologia, Universidade Estadual de Campinas)

2 Universidade Estadual de Campinas, Instituto de Biologia, Departamento de Botânica, C. Postal 6109, 13083-970 Campinas, SP, Brasil (Bolsa de Produtividade CNPq, processo 307132/2004-8)

3 Autor para correspondência: ttcastel@ccb.ufsc.br
} 
(Meijden \& Waals-Kooi 1979; Boorman \& Fuller 1984; Waite 1984; Klinkhamer \& De Jong 1988). Por outro lado, uma baixa cobertura vegetal pode aumentar a mobilidade do substrato e o soterramento e diminuir a taxa de germinação, emergência e sobrevivência de plântulas (Ernst 1981; Maun \& Lapierre 1986). Tanto o mar quanto o vento depositam e removem grandes quantidades de areia sobre as plântulas e sementes. A erosão, que pode expor o sistema radicular da plântula e causar dessecação (Maun 1994), pode também trazer sementes soterradas à superfície e restabelecer suas chances de emergência (Lee \& Ignaciuk 1985).

Em regiões tropicais, as dunas frontais são colonizadas principalmente por plantas perenes, dentre estas Ipomoea pes-caprae, com ampla ocorrência em praias tropicais (Wilson 1977; Devall \& Thien 1989). A espécie é encontrada logo após a linha de maré alta, onde sofre perturbações por invasão das marés de tempestade e soterramentos (Hueck 1955; Wilson 1977; Devall 1987). Aspectos sobre a ocorrência e o estabelecimento de plântulas desta espécie vêm sendo discutidos. Para Hueck (1955) e Reitz (1961), o estabelecimento de novos indivíduos por segmentos isolados de ramos é raro e, segundo Hueck (1955), apesar da alta predação por insetos, como a observada no litoral de São Paulo, a numerosa produção de sementes de Ipomoea pes-caprae permite a sua conservação nas regiões onde se fixou. Por outro lado, Wilson (1977), que também quantificou elevadas taxas de predação de sementes por besouros bruquídeos no litoral da Costa Rica, sugeriu que as populações devam ser mantidas por propagação vegetativa, com raro estabelecimento por sementes. Devall \& Thien (1989) registraram poucas plântulas em populações de Ipomoea pes-caprae no Golfo do México, sendo a maioria observada após tempestades. Esses autores discutiram que, como estas plantas podem ser mortas pelo mar, o estabelecimento por sementes deve ser importante para a recolonização. Devall et al. (1991) também registraram uma baixa densidade de plântulas em praias da Ilha St. George na Flórida, mas sugeriram um maior sucesso de estabelecimento de plântulas em praias em progressão de linha de costa. Bach (1998), ao registrar baixa densidade e baixa sobrevivência de plântulas de Ipomoea pes-caprae na costa australiana, concluiu que a dominância exercida por esta espécie se deve à sua propagação vegetativa e não ao recrutamento de plântulas.

Nas praias da Ilha de Santa Catarina, a predação de sementes de Ipomoea pes-caprae, tanto por larvas de besouros bruquídeos (Megacerus baeri e
M. reticulatus) quanto por lagartas de Ephestia kuhniella (Lepidoptera:Pyralidae) é frequientemente observada, podendo afetar até $65 \%$ das sementes produzidas (Castellani \& Santos 2005a). As sementes viáveis mostram alta longevidade no solo, podendo formar bancos permanentes de sementes, expressivos em algumas localidades (T.T. Castellani, dados não publicados). Na Ilha de Santa Catarina, a ocorrência de plântulas de Ipomoea pes-caprae é evidente em algumas praias. Desta forma, este estudo teve como objetivos avaliar: a) qual a ocorrência e a densidade de plântulas de Ipomoea pes-caprae em diferentes praias, b) se esta abundância está relacionada à densidade de ramos, sementes produzidas e ao estoque de sementes viáveis no solo e c) quais as taxas de sobrevivência e crescimento iniciais de plântulas e que fatores atuam na mortalidade.

\section{Material e métodos}

Espécie em estudo - Ipomoea pes-caprae é descrita como uma espécie perene de vida longa, mas seu tempo de vida não é conhecido (Devall 1992). A espécie apresenta um sistema de ramos longos (estolões) e curtos (Hueck 1955), com os ramos longos atingindo de 10 a 15 m (Wilson 1977) de comprimento. Estes estolões apresentam nós espaçados de 25 a $30 \mathrm{~cm}$ e nas extremidades $10 \mathrm{~cm}$. Nestes nós formam-se folhas e ramos curtos de até $0,5 \mathrm{~m}$ com folhas pouco distanciadas. Tanto os estolões como os ramos curtos podem se ramificar e apresentar inflorescências (Hueck 1955). Em Santa Catarina, a floração e frutificação de Ipomoea pes-caprae ocorrem nos meses de verão e outono (Santos \& Arruda 1995).

Ocorrência e densidade de plântulas na Ilha de Santa Catarina - A ocorrência de plântulas de Ipomoea pescaprae foi avaliada em 10 praias da Ilha de Santa Catarina $\left(27^{\circ} 22^{\prime} 45^{\prime \prime}-27^{\circ} 50^{\prime} 10^{\prime \prime}\right.$ S; 48 $21^{\prime} 37^{\prime \prime}$ 48³4'49” W): Lagoinha, Jurerê, Forte e Daniela, situadas no setor norte da ilha, Caieira da Barra do Sul no setor oeste, Pântano do Sul no setor sul e Armação, Joaquina, Galheta e Moçambique no setor leste. Estas praias apresentam diferentes extensões, variando de $214 \mathrm{~m}$ (Caieira da Barra do Sul) a $11.250 \mathrm{~m}$ (Moçambique), e em todas foi registrada a ocorrência de populações de Ipomoea pes-caprae (Castellani \& Santos 2005b).

Em cada praia, três manchas de Ipomoea pescaprae foram determinadas para estudo, considerando-se como manchas, áreas colonizadas pela 
espécie, descontínuas entre si. Para esta determinação, sorteou-se três distâncias ao longo da praia, marcando-se a mancha mais próxima ao ponto. $\mathrm{Na}$ Praia da Caieira da Barra do Sul, de menor extensão, a menor distância entre as manchas estudadas ficou em torno de $70 \mathrm{~m}$. Nas demais praias, as distâncias entre manchas foram sempre superiores a $300 \mathrm{~m}$. Uma transecção perpendicular ao mar foi estabelecida ao longo de cada mancha, cuja extensão era definida pelo início e fim da ocorrência de ramos de Ipomoea pes-caprae. A extensão destas manchas variava de 1 a $2 \mathrm{~m}$ na Praia da Caieira da Barra do Sul a $50 \mathrm{~m}$ na Praia da Joaquina (Castellani \& Santos 2005b). Quadrados de $1 \times 1 \mathrm{~m}$ foram dispostos de forma contínua ao longo da transecção, registrando-se o número de plântulas presentes em seis amostragens: janeiro, março, maio, agosto e dezembro/1996 e abril/1997.

A relação entre a densidade de plântulas e densidades de ramos, sementes produzidas e estoque de sementes viáveis no solo foi avaliada em maio de 1996. O número de ramos longos (estolões) e curtos de Ipomoea pes-caprae foi contado em cada quadrado de $1 \times 1 \mathrm{~m}$ e a produção de sementes foi estimada somando-se os frutos maduros, os com sementes em dispersão, os já dispersos e os frutos em fase final de amadurecimento $\times$ o número de sementes/ fruto $(\mathrm{n}=50$ frutos coletados por mancha). A densidade de sementes viáveis no solo foi avaliada com o uso de coletores de $14 \mathrm{~cm} \times 14 \mathrm{~cm} \times 16 \mathrm{~cm}$ profundidade (volume de $3.136 \mathrm{~cm}^{3}$ ). A cada $1 \mathrm{~m}$, ao longo da transecção, quatro amostras de solo foram retiradas, sendo estas coletadas à direita ou à esquerda de cada quadrado amostral, numa distância de até $50 \mathrm{~cm}$. A viabilidade destas sementes foi verificada submetendo-as à condições de germinação. As sementes foram colocadas em placas de Petri, com papel de filtro duplo umedecido e submetidas a luz constante e temperatura de $25^{\circ} \mathrm{C}$ em sala de cultivo. As sementes intactas que não germinaram após dois meses foram escarificadas com ácido sulfúrico P.A. (95\%-98\%) e retornaram à sala de cultivo por mais um mês, período suficiente para que as sementes viáveis germinassem. Para facilitar comparações com densidades estimadas para $1 \mathrm{~m}^{2}$ de superfície, os valores de densidade de sementes no solo foram convertidos para $0,16 \mathrm{~m}^{3}(1 \mathrm{~m} \times 1 \mathrm{~m} \times 16 \mathrm{~cm}$ profundidade).

Sobrevivência de plântulas - Plântulas de Ipomoea pes-caprae foram monitoradas em diferentes situações: a) em manchas de Ipomoea pes-caprae; b) em setor de alta praia, distante de plantas estabelecidas; c) em área em recolonização, onde o depósito arenoso foi removido e reconstruído e d) em área em recolonização, onde a mancha de Ipomoea pes-caprae foi parcialmente removida pelo mar. Plântulas associadas a manchas de Ipomoea pescaprae foram marcadas ao longo da duna frontal e acompanhadas na Praia da Daniela, em 1996, e no Pântano do Sul, Joaquina e Moçambique, em 1997. Plântulas germinadas na alta praia foram monitoradas nas praias da Daniela e Pântano do Sul, onde ocorreram episódios de germinação maciça, junto ao lixo de maré. Em fevereiro/1996, esse evento foi registrado na porção sul do pontal da Daniela, formando uma faixa de $17 \mathrm{~m}$ com agrupamentos de plântulas. Essas plântulas foram acompanhadas de três formas: 1) marcação e mapeamento em 3 quadrados de $50 \mathrm{~cm} \times 50 \mathrm{~cm}$; 2) mensuração e contagem em três moitas formadas pela agregação de plântulas e 3) contagem em três perfis de praia perpendiculares ao mar. Novo episódio de germinação ocorreu em dezembro/1996 e três moitas de plântulas foram monitoradas (método 2). O mesmo ocorreu no Pântano do Sul, onde uma transecção de $35 \mathrm{~m} \times 1 \mathrm{~m}$ foi estabelecida paralela ao mar, para contagem e monitoramento das plantas.

A recolonização por plântulas em áreas afetadas por erosão foi observada nas praias da Daniela e Moçambique. Na Daniela, a barra arenosa ocupada por uma mancha de Ipomoea pes-caprae foi totalmente destruída em junho/1996 e reconstruída em 1997, com ocorrência de plântulas a partir de abril. Em dezembro/1998, um ano e oito meses depois, as plântulas estabelecidas foram medidas para avaliar tamanho e ocupação. Em junho/1997, na Praia de Moçambique, o mar invadiu uma mancha de Ipomoea pes-caprae, removendo e soterrando a vegetação. Em dezembro/1997, observou-se a emergência de plântulas e 20 destas foram marcadas e avaliadas em amostragens sazonais até março/1999.

Crescimento de plântulas - Plântulas marcadas na Praia da Daniela foram avaliadas quinzenalmente quanto à presença de folhas cotiledonares, número de folhas e "comprimento" da plântula. Este foi considerado como a distância entre o meristema apical e a superfície da areia, envolvendo tanto o caule como o hipocótilo. Plântulas marcadas nas praias de Moçambique e Pântano do Sul foram avaliadas em amostragens sazonais.

Efeito do soterramento em plântulas no laboratório Lotes de 20 sementes recém-germinadas foram 
plantadas em quatro potes plásticos translúcidos de $250 \mathrm{~cm}^{2}$ e $15 \mathrm{~cm}$ de altura, em uma camada de $3 \mathrm{~cm}$ de areia e cobertas com $2 \mathrm{~cm}$ de areia. Após um mês de desenvolvimento, as 20 plântulas sobreviventes em cada pote foram medidas quanto ao comprimento do hipocótilo exposto, do ramo e número de folhas. As plântulas de um dos potes foram avaliadas quanto ao peso seco das raízes, hipocótilo, cotilédone, folhas e ramos, após secagem em estufa a $100{ }^{\circ} \mathrm{C}$ por $48 \mathrm{~h}$. Os três potes restantes foram destinados a um experimento de soterramento. Em um dos potes, as plântulas foram submetidas a um soterramento de $5 \mathrm{~cm}$, em outro a $10 \mathrm{~cm}$ e no terceiro nenhum soterramento foi aplicado. O soterramento de plântulas foi feito em 5 e $10 \mathrm{~cm}$, pois foram observadas plântulas soterradas nestas profundidades no monitoramento feito na alta praia da Daniela. O soterramento foi feito com areia seca procedente das dunas móveis da Praia da Joaquina, sendo aplicada às plântulas com auxílio de uma peneira. As plântulas foram mantidas em condições de laboratório, em bancada exposta à incidência de luz solar e condições de temperatura não controladas. Regas com água destilada foram feitas a cada três dias. Após um mês sob condições de soterramento, as plântulas sobreviventes foram novamente medidas para avaliar o crescimento e a biomassa.

\section{Resultados}

Ocorrência e densidade de plântulas na Ilha de Santa Catarina - Plântulas de Ipomoea pes-caprae ocorreram em nove $(90 \%)$ praias, com exceção da Caieira da Barra do Sul, sendo registradas em 21 (70\%) das 30 manchas monitoradas (Fig. 1). Em cinco praias (Lagoinha, Daniela, Joaquina, Moçambique e Pântano do Sul), todas as manchas tiveram pelo menos um episódio de emergência de plântulas. Em outras duas (Armação e Galheta), as plântulas ocorreram em duas manchas e nas praias restantes (Jurerê e Forte) ocorreram em apenas uma mancha (Fig. 1). Plântulas de Ipomoea pes-caprae ocorreram em todas as datas amostrais, não havendo diferenças significativas quanto ao número de praias $\left(\chi^{2}=4,00 ;\right.$ g.l. $\left.=5 ; \mathrm{P}>0,05\right)$ e de manchas $\left(\chi^{2}=4,60 ;\right.$ g.l. $\left.=5 ; \mathrm{P}>0,05\right)$ com presença de plântulas ao longo do tempo.

Quanto à densidade, esta variou de 0 a 5,2 plântulas $\mathrm{m}^{2}$, com maiores valores na Praia da Daniela, em mancha (T3) posteriormente destruída pelo mar no outono de 1996. Valores elevados ( $>1$ plântula $\mathrm{m}^{2}$ ) ocorreram em outras duas praias (Moçambique e Pântano do Sul), em meses de primavera, verão e outono (Fig. 1). A densidade de plântulas de Ipomoea pes-caprae não mostrou relação com a densidade de ramos nas manchas $\left(r_{s}=0,21\right.$; $\mathrm{P}>0,05)$, que apresentou valores entre 2,8 a 25,3 ramos $\mathrm{m}^{2}$. Também não se observou uma correlação significativa entre a densidade de plântulas e o número de sementes produzidas $\left(\mathrm{r}_{\mathrm{s}}=0,31 ; \mathrm{P}>0,05\right)$, mas houve certa correlação com a densidade de sementes viáveis no solo $\left(\mathrm{r}_{\mathrm{s}}=0,46 ; \mathrm{P}<0,05\right)$. Nas manchas de Ipomoea pes-caprae estudadas a densidade de sementes produzidas variou de 0 a $112,4 \mathrm{~m}^{2}$ e a de sementes viáveis no solo variou de 0 a 90,5 sementes $\mathrm{m}^{2}$.

Sobrevivência de plântulas - Em manchas de Ipomoea pes-caprae, um total de 119 plântulas foi monitorado em coortes emergidas em 1996 e 1997 e apenas uma $(0,84 \%)$ sobreviveu. A erosão e uma aparente dessecação foram os principais fatores de mortalidade. Na Praia da Daniela, a ação erosiva do outono de 1996 destruiu a barra arenosa onde as plântulas $(\mathrm{n}=99)$ se desenvolviam. Estas não sobreviveram por mais que cinco meses, sendo afetadas pela primeira invasão do mar em maio e totalmente removidas em junho (24/06/1996), após nova ação erosiva. Também nas praias da Joaquina $(n=11)$ e Moçambique $(n=4)$, as plântulas morreram pela ação marinha, que destruiu parte das dunas frontais em junho/1997, e por dessecação. Estas plantas não sobreviveram mais que quatro meses. A plântula que sobreviveu por mais de um ano, no Pântano do Sul $(n=5)$, se estabeleceu no período de dezembro/1997 a abril/1999, quando não ocorreram eventos erosivos sobre a área.

No setor de alta praia, nenhuma plântula sobreviveu, tendo-se monitorado em dois anos 2.684 plântulas com os diferentes métodos. Em 1996, no pontal da Daniela, 1.609 plântulas foram acompanhadas: 1.269 em três moitas formadas por plântulas, 85 nos quadrados permanentes e 255 nos três perfis de praia. Todas as plântulas morreram pela ação da erosão. Uma acentuada mortalidade ocorreu na primeira invasão do mar em maio (3/05/1996), sem sobreviventes após seis meses de vida. Estas plântulas sofreram tanto soterramento quanto remoção de areia. Em 18/07/1996, as plântulas monitoradas em moitas estavam soterradas entre 6 e $10 \mathrm{~cm}$ de profundidade. Em 11/08/1996, a deposição de areia se reduziu, mas as plântulas estavam mortas. Também as plântulas germinadas na alta praia em dezembro/1996 no Pântano do Sul $(\mathrm{n}=30)$ e nas moitas de plântulas no Pontal da Daniela $(n=1.045)$ foram removidas por marés altas no outono de 1997. 
Nos perfis de praia amostrados no Pontal da Daniela em 1996, apenas uma plântula foi registrada junto às plantas adultas de Ipomoea pes-caprae. Considerando as 255 plantas registradas, estas distavam, em média, $8,8 \mathrm{~m}( \pm 3,4)$ das plantas estabelecidas. No perfil 1 , as plântulas $(n=140)$ estavam a 23,0 $\mathrm{m}( \pm 3,2)$ do mar e os adultos a 33,8 $\mathrm{m}$ $( \pm 2,5)$. No perfil 2 , as plântulas $(n=63)$ distavam

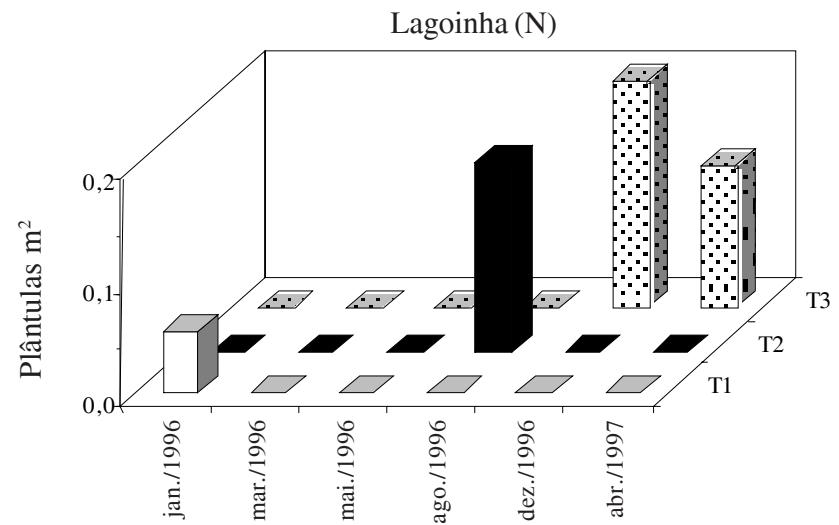

Jurerê (N)

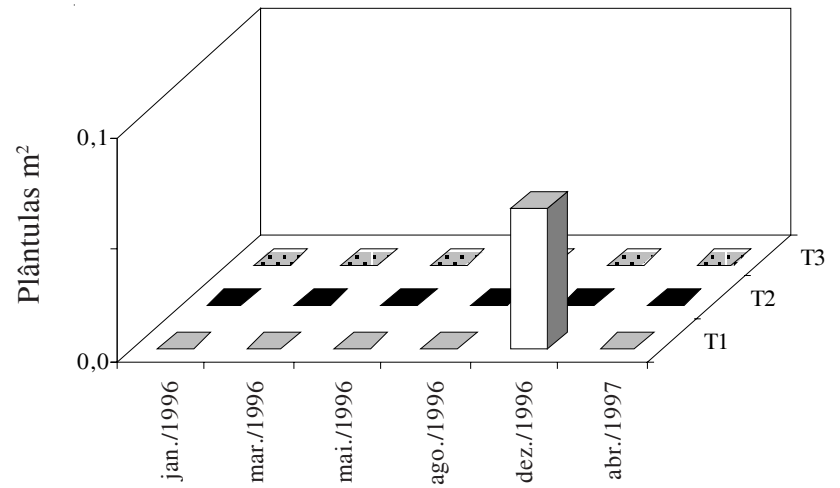

$19,6 \mathrm{~m}( \pm 0,4)$ do mar e os adultos $24,6 \mathrm{~m}( \pm 1,4)$ e no perfil três $(\mathrm{n}=52)$ estas distâncias eram $20,1 \mathrm{~m}( \pm 1,4)$ e $28,00 \mathrm{~m}( \pm 0,3)$, respectivamente.

Nas áreas em recolonização, $16(80 \%)$ das 20 plântulas acompanhadas em Moçambique de dezembro/1997 a março/1999 sobreviveram por mais de um ano (Tab. 1). Na Praia da Daniela, em dezembro/1998, quatro plantas com idade aproximada
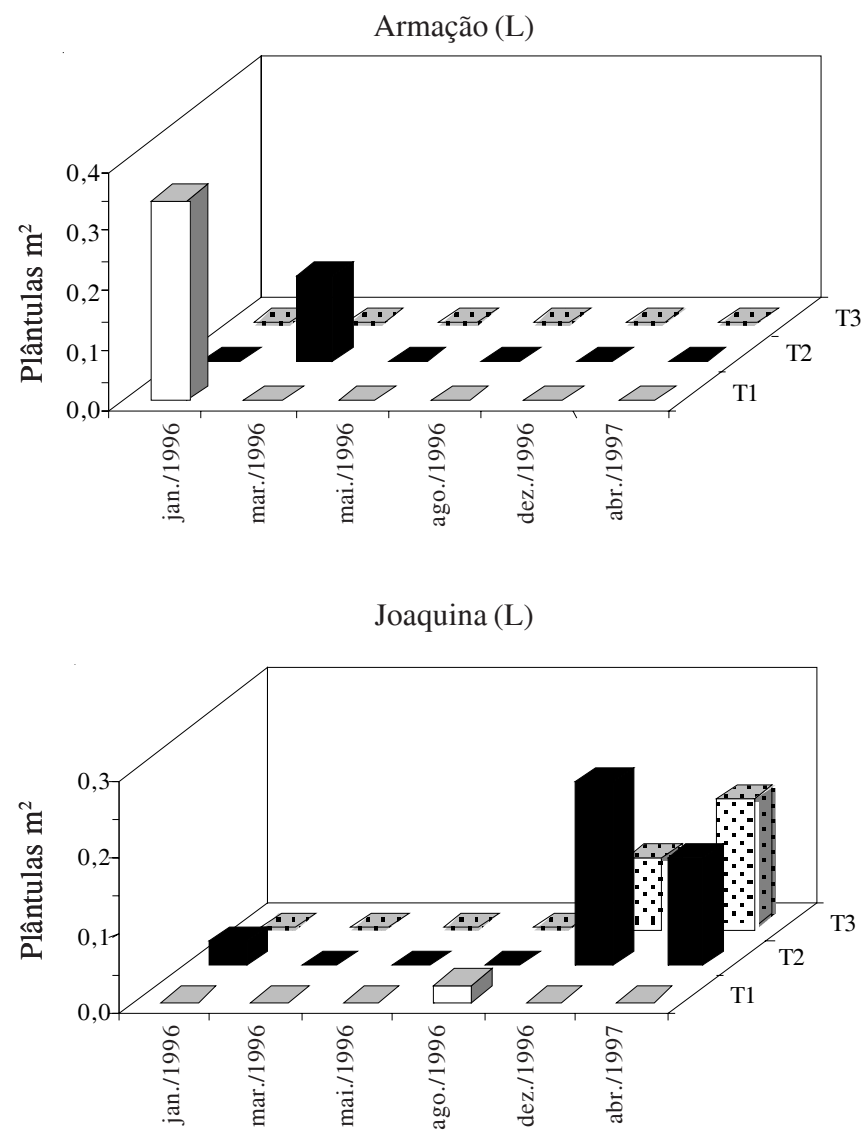

Pântano do Sul (S)

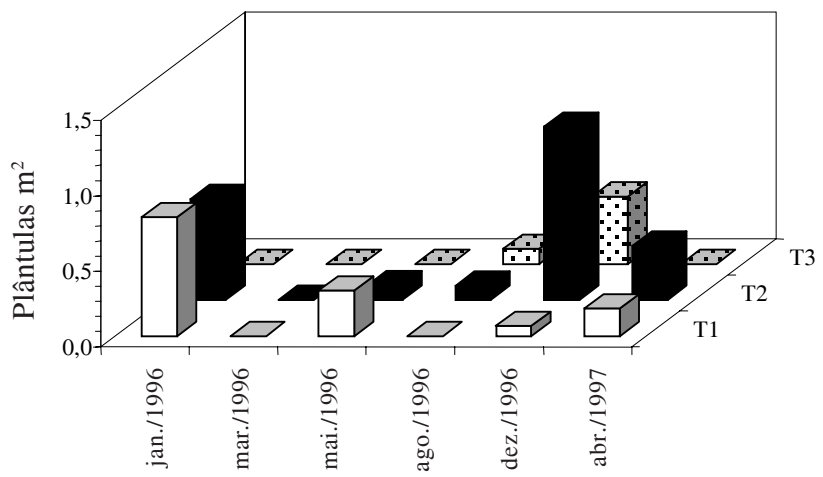

Figura 1. Densidade de plântulas de Ipomoea pes-caprae (L.) R. Br. em três manchas (T1, T2 e T3) monitoradas em praias dos setores norte (N), leste (L) e sul (S) da Ilha de Santa Catarina, SC. A praia da Caieira da Barra do Sul (setor oeste), sem ocorrência de plântulas no período de estudo, não foi incluída. 
Tabela 1. Crescimento de plântulas de Ipomoea pes-caprae (L.) R. Br. germinadas em dezembro/1997 na praia de Moçambique, Ilha de Santa Catarina, SC. São apresentadas as médias e desvio-padrão de diferentes estruturas. ${ }^{*}$ Cicatrizes de queda foliar.

\begin{tabular}{|c|c|c|c|c|c|c|}
\hline Plantas sobreviventes & $\begin{array}{c}2 / 12 / 97 \\
20\end{array}$ & $\begin{array}{c}13 / 3 / 98 \\
19\end{array}$ & $\begin{array}{c}20 / 5 / 98 \\
18\end{array}$ & $\begin{array}{c}10 / 9 / 98 \\
18\end{array}$ & $\begin{array}{c}16 / 11 / 98 \\
18\end{array}$ & $\begin{array}{c}17 / 3 / 99 \\
16\end{array}$ \\
\hline \multicolumn{7}{|l|}{ Ramo primário } \\
\hline Comprimento (cm) & $1,5 \pm 0,8$ & $8,1 \pm 3,2$ & $9,1 \pm 4,5$ & $11,4 \pm 5,3$ & $11,9 \pm 5,7$ & $18,1 \pm 8,6$ \\
\hline Número de folhas & $2,3 \pm 1,5$ & $4,9 \pm 2,5$ & $4,0 \pm 2,4$ & $2,6 \pm 1,7$ & $2,4 \pm 2,3$ & $2,8 \pm 2,9$ \\
\hline Número de cicatrizes* & 0 & $6,0 \pm 2,1$ & $9,9 \pm 3,9$ & $13,2 \pm 4,5$ & $15,2 \pm 5,2$ & $19,6 \pm 5,4$ \\
\hline Número de brotos/planta & 0 & $0,3 \pm 0,6$ & $0,7 \pm 1,0$ & $0,9 \pm 1,4$ & $1,1 \pm 1,1$ & $1,8 \pm 1,5$ \\
\hline \multicolumn{7}{|l|}{ Brotos } \\
\hline Comprimento (cm) & - & $3,3 \pm 2,1$ & $3,7 \pm 2,9$ & $6,0 \pm 4,8$ & $5,6 \pm 5,8$ & $11,5 \pm 8,4$ \\
\hline Número de folhas & - & $4,0 \pm 2,1$ & $2,9 \pm 1,8$ & $2,1 \pm 2,1$ & $2,0 \pm 2,0$ & $4,6 \pm 4,0$ \\
\hline Número de cicatrizes & - & 0 & $2,4 \pm 2,9$ & $4,8 \pm 5,0$ & $4,4 \pm 4,6$ & $3,5 \pm 3,6$ \\
\hline \multicolumn{7}{|l|}{ Total por planta } \\
\hline Número de folhas & $2,3 \pm 1,5$ & $6,2 \pm 1,8$ & $6,1 \pm 1,9$ & $4,6 \pm 2,2$ & $4,6 \pm 2,0$ & $10,8 \pm 7,8$ \\
\hline Número de cicatrizes & 0 & $6,0 \pm 2,1$ & $10,3 \pm 4,1$ & $15,0 \pm 5,8$ & $17,9 \pm 7,1$ & $22,3 \pm 8,2$ \\
\hline
\end{tabular}

de um ano e oito meses mostravam-se estabelecidas sobre a barra arenosa reconstruída (Tab. 2). Nenhuma dessas plantas, no entanto, mostrava sinais de reprodução com esse tempo de desenvolvimento.

Sem considerar as quatro plântulas que recolonizaram a T3 da Praia da Daniela, 2.823 plântulas foram acompanhadas em três anos, com 17 sobrevivendo até um ano e quatro meses de idade. Estas estabeleceram-se no período de dezembro/1997 a abril/1999 e representam $0,6 \%$ do total examinado.

Crescimento de plântulas - A maioria das plântulas monitoradas na Praia da Daniela não sobreviveu mais que seis meses, mas permitiu uma avaliação do crescimento inicial. As acompanhadas em mancha de Ipomoea pes-caprae mantiveram as folhas cotiledonares por até dois meses de desenvolvimento, quando tinham 2 folhas/plântula e comprimento em torno de $5 \mathrm{~cm}$. Com quatro meses de desenvolvimento, as sobreviventes apresentavam cerca de $7 \mathrm{~cm}$ e menos de 1 folha/planta, estando danificadas pela invasão marinha. As plântulas da alta praia também mostraram permanência das folhas cotiledonares por cerca de dois meses. Essas plântulas, no entanto, mostraram uma variação de tamanho que reflete os soterramentos sofridos. No final de maio, a acentuada redução do comprimento médio decorreu do fato de o meristema de várias plantas estar abaixo da superfície (Fig. 2).

As plântulas que sobreviveram por um ano e quatro meses na Praia de Moçambique, atingiram cerca de

Tabela 2. Tamanho de quatro indivíduos genéticos de Ipomoea pes-caprae (L.) R. Br. em dezembro/1998, com idade aproximada de um ano e oito meses, em barra arenosa recente (T3), Praia da Daniela, Ilha de Santa Catarina, SC. Valores em ( ) representam raízes grossas, com diâmetro de um dedo e valores em \{ \} representam ramos curtos ressecados. ${ }^{*}$ Cicatrizes de queda foliar.

\begin{tabular}{|c|c|c|c|c|c|c|c|c|c|}
\hline \multirow[b]{2}{*}{ Estolão } & \multicolumn{3}{|c|}{ Planta 1} & \multicolumn{4}{|c|}{ Planta 2} & \multirow{2}{*}{ Planta 3} & \multirow{2}{*}{$\frac{\text { Planta } 4}{1}$} \\
\hline & 1 & 2 & 3 & Total & 1 & 2 & Total & & \\
\hline Comprimento (cm) & 155,0 & 750,7 & 142,0 & - & 600,0 & 260,0 & - & 105,0 & 60,0 \\
\hline Número de nós & 22 & 69 & 31 & 122 & - & - & - & 32 & 30 \\
\hline Distância média entre nós (cm) & 7,1 & 10,9 & 4,6 & - & - & - & - & 3,3 & 2,0 \\
\hline Número de folhas & 1 & 39 & 31 & 71 & 49 & 24 & 73 & 31 & 24 \\
\hline Número de raízes & $1^{(1)}$ & $17^{(4)}$ & 0 & $18^{(5)}$ & - & - & - & 0 & 0 \\
\hline Número de ramos curtos & $15^{\{2\}}$ & $43^{\{2\}}$ & 0 & $58^{\{4\}}$ & 22 & 19 & 41 & 3 & 4 \\
\hline Comprimento médio (cm) & 7,2 & 11,9 & - & 10,7 & 17,9 & 6,8 & 9,6 & 20,7 & 24,6 \\
\hline Número médio de folhas & 3,5 & 5,6 & - & 5,1 & 6,4 & 3,3 & 4,9 & 6,3 & 9,8 \\
\hline Número médio de cicatrizes* & 3,5 & 1,0 & - & 1,6 & 0 & 0 & 0 & 0 & 0 \\
\hline Total de folhas nos ramos & 53 & 243 & - & 296 & 140 & 62 & 202 & 19 & 39 \\
\hline Total de cicatrizes nos ramos & 52 & 42 & - & 94 & 0 & 0 & 0 & 0 & 0 \\
\hline
\end{tabular}


$18 \mathrm{~cm}, 10$ folhas/planta tendo cerca de dois brotos secundários. Estes aumentaram no verão de 1999, após um ano de desenvolvimento (Tab. 1). Dentre essas plantas, a de maior extensão tinha $35 \mathrm{~cm}$, mantendo-se com aspecto de ramo curto e não de estolão. A plântula estabelecida no Pântano do Sul, sob mancha de Ipomoea pes-caprae, apresentava $15 \mathrm{~cm}$ e quatro folhas, para o mesmo tempo de desenvolvimento. Já as plântulas estabelecidas no Pontal da Daniela desenvolveram estolão após um ano e oito meses de desenvolvimento. A de maior porte possuía três estolões, cinco raízes bem desenvolvidas, 58 ramos curtos e 367 folhas (Tab. 2), ocupando uma área de 5,3 $\mathrm{m}^{2}$.

Efeito do soterramento em plântulas no laboratório As plântulas com um mês de desenvolvimento apresentavam caule em expansão, cerca de duas folhas e cotilédones foliares persistentes. A altura do hipocótilo estava em torno de $5 \mathrm{~cm}$ e a do caule, entre 2 e $4 \mathrm{~cm}$ (Fig. 3). Submetidas a soterramentos a $10 \mathrm{~cm}$, nenhuma plântula sobreviveu, enquanto $10(50 \%)$
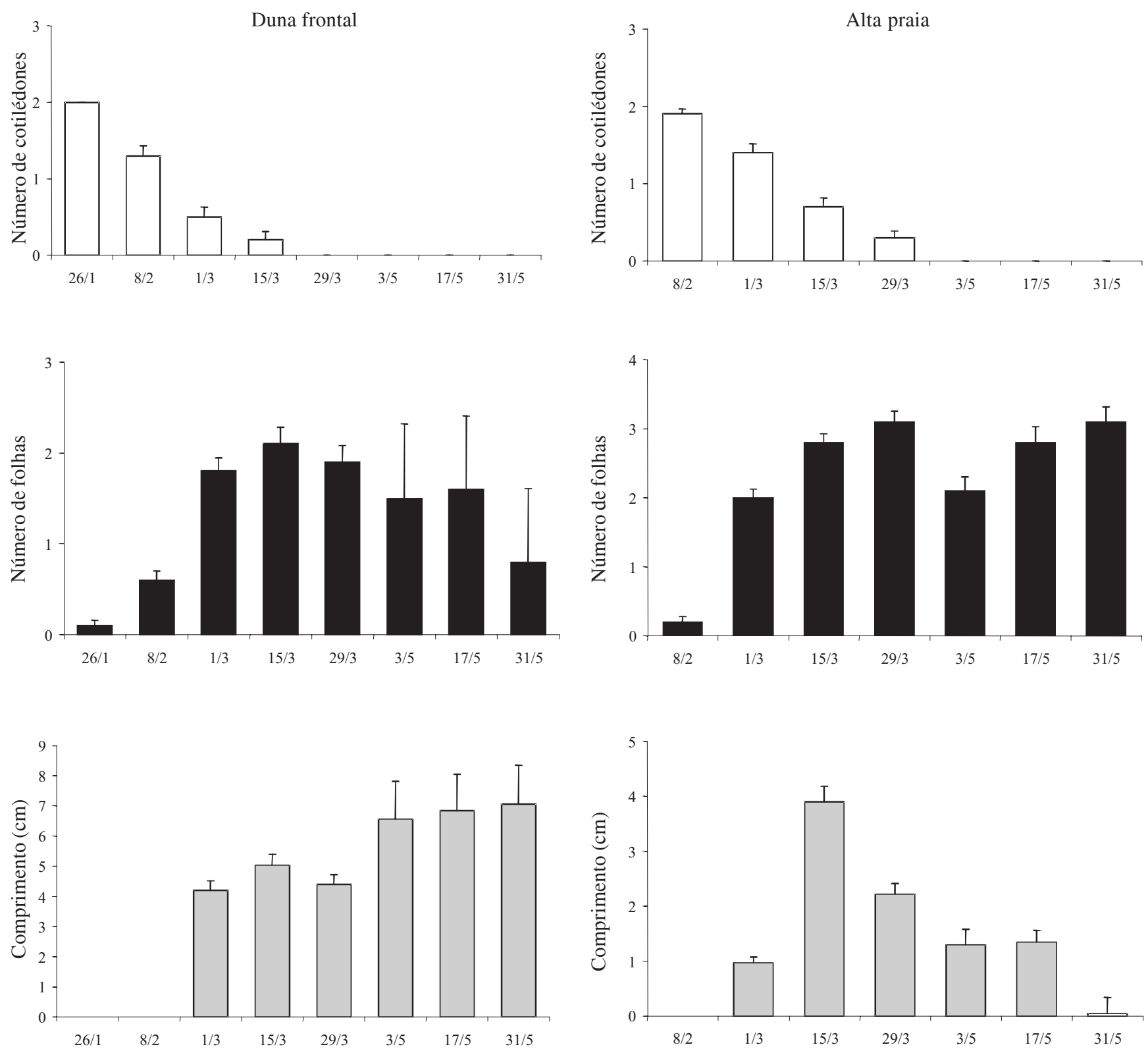

Figura 2. Número médio (e erro padrão) de cotilédones remanescentes, folhas e comprimento de plântulas de Ipomoea pes-caprae (L.) R. Br. germinadas na duna frontal, em mancha colonizada pela espécie (esquerda) e na alta praia (direita). Praia da Daniela, Ilha de Santa Catarina, SC 
sobreviveram à deposição de $5 \mathrm{~cm}$ de areia. Todas as 20 plântulas não soterradas sobreviveram. As plântulas que sobreviveram ao soterramento a $5 \mathrm{~cm}$ mostraram menor número de folhas cotiledonares remanescentes $(\mathrm{t}=4,81 ; \mathrm{P}<0,001)$ e menor número de folhas/plântula $(\mathrm{t}=2,13 ; \mathrm{P}<0,05)$ que as não soterradas. Ocorreu maior expansão do hipocótilo $(\mathrm{t}=2,99 ; \mathrm{P}<0,05)$ e menor alongamento das raízes $(\mathrm{t}=2,40 ; \mathrm{P}<0,05)$ nas plântulas soterradas, sem diferenças significativas quanto ao comprimento médio de caule $(\mathrm{t}=1,75 ; \mathrm{P}>0,05)$. A biomassa das plântulas soterradas foi menor $(\mathrm{t}=3,62 ; \mathrm{P}<0,05)$, ocorrendo diferenças significativas para todas as estruturas avaliadas (valores de " $\mathrm{t}$ " de 3,88 a 2,20; $\mathrm{P}<0,05)$. Nas plântulas não soterradas houve diferença no peso seco alocado para cada estrutura $\left(\mathrm{F}_{3,76}=14,98 ; \mathrm{P}<0,001\right)$, sendo a biomassa das raízes $>$ caule e folhas $>$ hipocótilo $=$ cotilédones (teste SNK, valor crítico em $\mathrm{P}=0,05)$. Sob soterramento também houve diferenças $\left(\mathrm{F}_{3,36}=4,24 ; \mathrm{P}<0,05\right)$, porém um menor desenvolvimento das raízes, tendo-se um peso seco de raízes $=$ caule e folhas $>$ hipocótilo $=$ cotilédones (teste $\mathrm{SNK}$, valor crítico em $\mathrm{P}=0,05$ ) (Fig. 3).
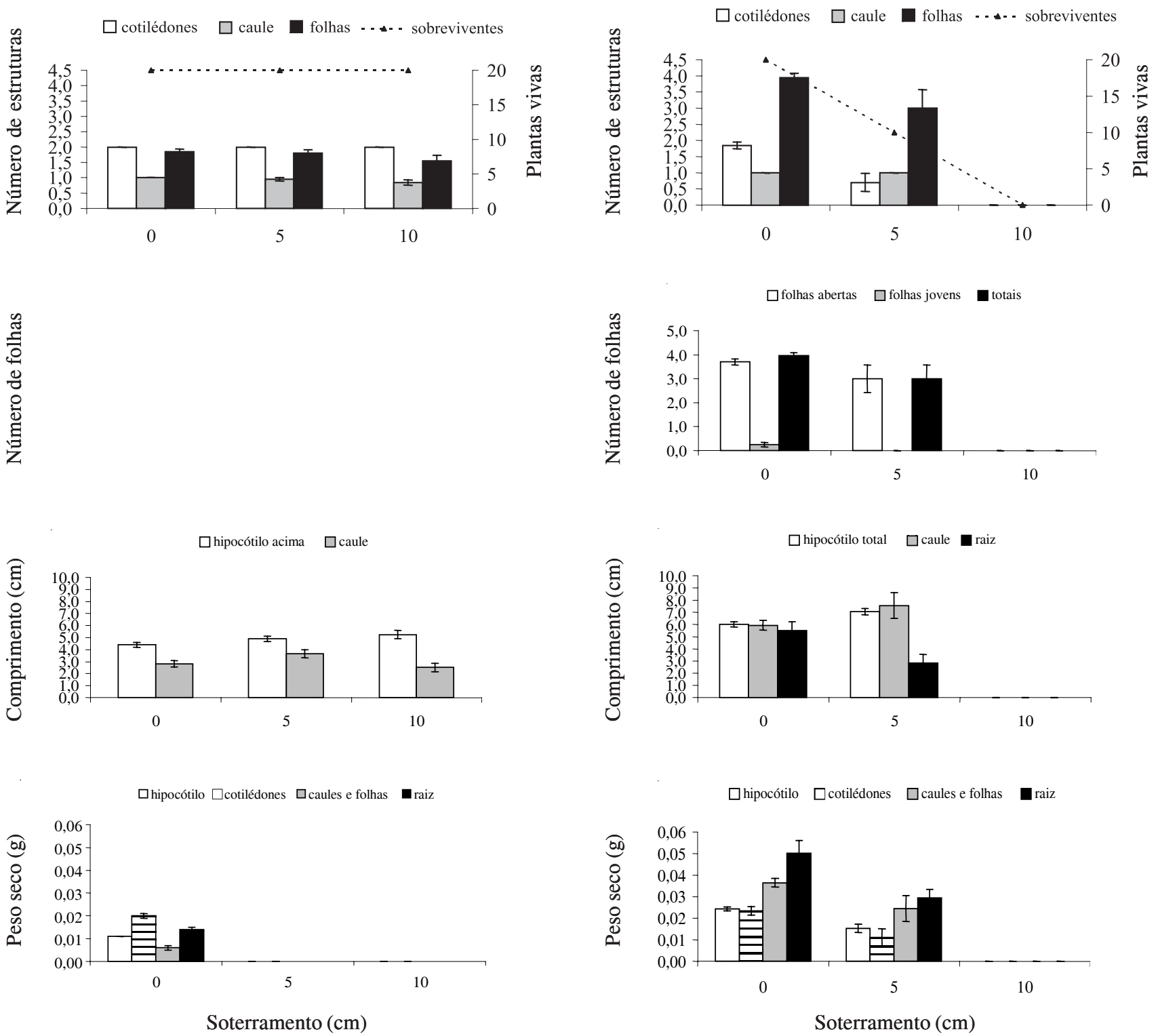

Figura 3. Número de sobreviventes e parâmetros de crescimento (média e erro padrão) avaliados em plântulas de Ipomoea pes-caprae (L.) R. Br., submetidas a diferentes níveis de soterramento por um mês (à direita). Os gráficos à esquerda referem-se às plântulas no início de cada tratamento com um mês de desenvolvimento. 


\section{Discussão}

Plântulas de Ipomoea pes-caprae ocorreram na maioria das praias, com emergência ao longo de todo o ano, não sendo raras como sugerido por Wilson (1977), Devall \& Thien (1989) e Devall et al. (1991). Devall \& Thien (1989) referiram-se a densidades de 0 a 0,02 plântulas $\mathrm{m}^{2}$ para cinco localidades no Golfo do México e Bach (1998) a 1 plântula $\mathrm{m}^{2}$ para uma localidade na costa australiana. Nas manchas de Ipomoea pes-caprae na Ilha de Santa Catarina, as densidades máximas estiveram acima deste último valor, variando de 0 a 5 plântulas $\mathrm{m}^{2}$. Nos episódios de germinação maciça que ocorreram na alta praia, no entanto, houve formação de pequenas moitas que atingiram densidades de 150 plântulas $\mathrm{m}^{2}$.

As diferenças de densidade de plântulas entre manchas de Ipomoea pes-caprae não são necessariamente explicadas pelas diferenças de densidade de ramos e de produção de sementes nas manchas, estando mais relacionadas ao estoque de sementes viáveis no solo. Este fato poderia sugerir certa importância dos predadores de sementes (Megacerus baeri, M. reticulatus e Ephestia kuhniella) limitando a abundância de plântulas, uma vez que seus danos reduzem o número de sementes viáveis que irão compor o estoque de sementes do solo (Castellani \& Santos 2005a).

No entanto, a densidade de plântulas registradas é pequena em relação ao estoque de sementes viáveis nas manchas. O fato de Ipomoea pes-caprae necessitar de escarificação para germinar (Devall \& Thien 1989) pode, em parte, explicar a baixa densidade de plântulas, uma vez que sementes intactas podem ter germinação retardada. Devall et al. (1991) comentam a ação abrasiva que a areia possa ter sobre as sementes de Ipomoea pes-caprae, o que pode aumentar a sua germinação. No entanto, experimentos feitos para avaliar a longevidade de sementes de Ipomoea pes-caprae em solo de duna, mostram que cerca de $75 \%$ das sementes podem se manter intactas sem germinar, após 3 anos. O soterramento das sementes é outro fator que pode limitar a abundância de plântulas. Apesar de Ipomoea pes-caprae poder germinar no escuro e emergir de profundidades de até $14 \mathrm{~cm}$, o soterramento pode reduzir esses eventos (T.T. Castellani, dados não publicados).

Tanto no campo quanto no laboratório ocorreu alta mortalidade de plântulas de Ipomoea pes-caprae sob soterramento. Maun $(1994 ; 1998)$ relata que, quando as plântulas são totalmente soterradas, as chances de emergência e sobrevivências são baixas, como observado nas espécies de duna Elymus farctus, Agropyron psammophllum, Cirsium pitcheri e Panicum virgatum. Sykes \& Wilson (1990) em estudo com 30 espécies de plantas de dunas do litoral da Nova Zelândia mostraram que o soterramento total de plântulas de dois meses de desenvolvimento acarretavam a morte da maioria destas.

Experimentos de soterramento realizados por Martínez \& Moreno-Casasola (1996) com plântulas de Ipomoea pes-caprae com seis semanas de desenvolvimento não mostraram diferenças na biomassa produzida em plantas submetidas a soterramento, o que diferiu de nosso estudo com plântulas com quatro semanas. Neste, a redução de biomassa nas plântulas soterradas a $5 \mathrm{~cm}$ parece relacionada à perda precoce das folhas cotiledonares, que auxiliam no desenvolvimento inicial da planta, e na redução do número de folhas, discutida como um resposta inicial das plântulas a soterramentos (Maun 1998). Martínez \& Moreno-Casasola (1996) encontraram, no entanto, uma tendência de redução da razão biomassa radicular/biomassa aérea para Ipomoea pes-caprae submetida a soterramento, também observada em nosso estudo. Esta tendência foi registrada para outras três espécies estudadas por estes autores, Chamaecrista chamaecristoides, Schizachyrium scoparium e Canavalia rosea, sendo discutida como uma mudança morfológica que permite às plantas emergirem ao soterramento. $\mathrm{O}$ mesmo foi registrado para Canavalia rosea por Fáveri \& Castellani (1998) e para Desmoschoenus spiralis, Elymus farctus, Euphorbia glauca, Hydrocotyle novae-zelandiae, Poa pusilla e Senecio elegans por Sykes \& Wilson (1990).

A sobrevivência de plântulas de Ipomoea pescaprae foi baixa, em torno de $0,6 \%$, se considerarmos o total monitorado em três anos. As principais causas de mortalidade foram a erosão e a deposição marinha, fatores limitantes ao estabelecimento de plantas de duna (Maun 1994; 1998). Os valores obtidos foram inferiores aos apresentados por Bach (1998), que encontrou $17 \%$ de sobrevivência $(n=100)$, baixo vigor das sobreviventes, mas monitorou as plantas por apenas 77 dias.

Se considerarmos as plântulas monitoradas nos diferentes anos ou se considerarmos as taxas de sobrevivência nas diferentes situações de estabelecimento encontradas, observa-se uma acentuada variação de taxas e essas diferenças parecem associadas à ocorrência ou não de eventos erosivos. 
Sugere-se que o fator-chave para o sucesso de estabelecimento de plântulas seja a estabilidade do hábitat, ou seja, quanto tempo o hábitat permanece sem perturbação marinha. Neste sentido, Devall et al. (1991) mostraram que praias com altas taxas de acresção (15 m ano) têm densidade de plântulas similar à de praias estáveis, mas que a densidade de indivíduos genéticos é maior, o que sugere maior estabelecimento em praias em progressão. Na Ilha de Santa Catarina, muitas praias encontram-se em processo de regressão da linha de costa (Abreu de Castilhos \& Gré 1997; Leal et al. 1998), o que se relaciona às baixas taxas de estabelecimento. No entanto, o fato de esse recuo poder ocorrer por episódios de erosão e posterior deposição de areia, como ocorrido na Praia da Daniela, disponibiliza novas áreas para colonização, onde uma plântula de Ipomoea pes-caprae pode desenvolver três estolões e ocupar $5 \mathrm{~m}^{2}$ no prazo de um ano e oito meses.

Neste estudo, ocorreu estabelecimento de plântulas de Ipomoea pes-caprae em uma barra arenosa recémestabelecida, em área onde o mar removeu parcialmente a mancha de Ipomoea pes-caprae e em área de duna frontal, sob mancha de Ipomoea pes-caprae não perturbada pelo mar. Diferenças no crescimento das plântulas indicam uma maior rapidez de colonização em áreas recentes e nuas, mas o recrutamento pode ocorrer nas três condições distintas.

Eriksson (1989) propôs dois padrões extremos para o recrutamento de plântulas de espécies clonais: ISR ("initial seedling recruitment") onde não há recrutamento em manchas com adultos estabelecidos e RSR ("repeated seedling recruitment") onde há este recrutamento. Cerca de $40 \%$ das espécies clonais ajustam-se ao tipo RSR e $60 \%$ ao ISR, podendo ocorrer variações entre populações de uma mesma espécie. Erikson (1993) adicionou a esses modelos o recrutamento dependente de perturbações, uma vez que estas causariam a remoção total, parcial ou nenhuma, dos "genetas" presentes nas manchas. As evidências de recrutamento de plântulas de Ipomoea pes-caprae podem sugerir qualquer um dos três modelos, sendo a taxa de crescimento dos jovens, no entanto, maior onde houve total remoção dos indivíduos genéticos, que associamos à colonização da barra arenosa no pontal da Daniela. Características de vida de Ipomoea pes-caprae são compatíveis às três estratégias. Ipomoea pes-caprae possui sementes que se dispersam a longas distâncias pelo mar (Guppy 1917 apud Devall \& Thien 1989) e que permitem colonizar novas áreas. Essa capacidade é esperada para espécies ISR (Eriksson 1989; 1993). As sementes não removidas pelo mar podem formar bancos de sementes permanentes (T.T. Castellani, dados não publicados), o que é esperado em espécies ISR e para aquelas que regeneram após perturbações que removem parcialmente os "genetas" das manchas locais (Eriksson 1989; 1993). Para espécies RSR, espera-se uma capacidade de regenerar sob os "genetas" estabelecidos (Eriksson 1989; 1993) e as sementes grandes de Ipomoea pes-caprae e a ausência de luz para germinar podem também permitir este tipo de estabelecimento.

Conclui-se, então, que Ipomoea pes-caprae é capaz de regenerar sob diferentes situações, mas o sucesso desta regeneração não está apenas relacionado à presença ou não dos "genetas", mas também à duração da estabilidade do hábitat onde esta germinou, ou seja, ao tempo em que perdurarem condições sem erosão.

\section{Referências bibliográficas}

Abreu de Castilhos, J. \& Gré, J.C.R. 1997. Praias da Ilha de Santa Catarina: caracterização morfológica e problemas de erosão costeira. Pp. 107-113. In: Colóquio Francobrasileiro sobre manejo costeiro da Ilha de Santa Catarina. Florianópolis 1977. Florianópolis, UFSCUniversité Bordeux 1.

Bach, C.E. 1998. Seedling survivorship of the beach morning glory, Ipomoea pes-caprae (Convolvulaceae). Australian Journal of Botany 46(1): 123-133.

Bernardi, H.; Cordazzo, C.V. \& Costa, C.S.B. 1987. Efeito de ressacas sobre Blutaparon portulacoides (St. Hill.) Mears, nas dunas costeiras do sul do Brasil. Ciência e Cultura 39(5/6): 545-547.

Bernardi, H. \& Seeliger, U. 1989. Population biology of Blutaparon portulacoides (St. Hill.) Mears on southern Brazilian backshores. Ciência e Cultura 41(11): 1110-1113.

Boorman, L.A. \& Fuller, R.M. 1984. The comparative ecology of two sand dune biennials: Lactuca virosa L. and Cynoglossum officinale L. New Phytologist 69: 609-629.

Castellani, T.T.; Folchini, R. \& Scherer, K.Z. 1995. Variação temporal da vegetação em um trecho de baixada úmida entre dunas, Praia da Joaquina, Florianópolis, SC. Insula 24: 37-72.

Castellani T.T. \& Santos, F.A.M. 2005a. Fatores de risco à produção de sementes de Ipomoea pes-caprae. Revista Brasileira de Botânica 28(4): 773-783.

Castellani T.T. \& Santos, F.A.M. 2005b. Abundância de ramos reprodutivos e produção de sementes em populações de Ipomoea pes-caprae (L.) R. Br. na Ilha de Santa Catarina, Brasil. Acta Botanica Brasilica 19(2): 251-264. 
Castellani, T.T.; Scherer, K.Z. \& Paula, G.S. 2001. Population ecology of Paepalanthus polyanthus (Bong.) Kunth: demography and life history of a sand dune monocarpic plant. Revista Brasileira de Botânica 24(2): 123-134.

De Jong, T.J. \& Klinkhamer, P.G.L. 1988. Population ecology of the biennials Cirsium vulgare and Cynoglossum officinale in a coastal sand-dune area. Journal of Ecology 76: 366-382.

Devall, M.S. 1987. Ecology of Ipomoea pes-caprae (Convolvulaceae) at Grand Isle, Louisiana. Proceedings of Louisiana Academy of Science 50: 7-12.

Devall, M.S. \& Thien, L.B. 1989. Factors influencing the reproductive success of Ipomoea pes-caprae (Convolvulaceae) around the Gulf of Mexico. American Journal of Botany 76(12): 1821-1831.

Devall, M.S.; Thien, L.B. \& Platt, W.J. 1991. The ecology of Ipomoea pes-caprae, a pantropical strand plant. Pp. 231-249. In: Proceedings of the Symposium on coastal sand dunes. Ontario 1990. Ontario, University of Guelph.

Eriksson, O. 1989. Seedling dynamics and life histories in clonal plants. Oikos 55: 231-238.

Eriksson, O. 1993. Dynamics of genets in clonal plants. Trends in Ecology and Evolution 8(9): 313-316.

Ernst, W.H.O. 1981. Ecological implication of fruit variability in Phleum arenarium L., an annual dune grass. Flora 171: 387-398.

Fáveri, S.B. \& Castellani, T.T. 1998. Efeitos do soterramento no desenvolvimento e estabelecimento de plântulas de Canavalia rosea. Pp. 104-115. In: Anais do IV Simpósio de Ecossistemas Brasileiros. Águas de Lindóia 1998. São Paulo, ACIESP, v. III.

Hueck, K. 1955. Plantas e formação organogênica das dunas no litoral paulista - Parte 1. São Paulo, Instituto de Botânica.

Johnson, A.F. 1985. Ecologia de Abronia maritima, especie pionera de las dunas del oeste de Mexico. Biotica 10(1): 19-34.

Klinkhamer, P.G. \& De Jong, T.J. 1988. The importance of small scale disturbance for seedling establishment in Cirsium vulgare and Cynoglossum officinale. Journal of Ecology 76: 383-392.
Leal, P.C.; Horn Filho, N.O. \& Oliveira, J.S. 1998. Evidências erosivas no setor centro-norte da praia de Moçambique, Ilha de Santa Catarina, Santa Catarina, Brasil. Geosul 14(27): 229-231.

Lee, J.A. \& Ignaciuk, R. 1985. The physiological ecology of strandline plants. Vegetatio 62: 319-326.

Martínez, M.L. \& Moreno-Casasola, P. 1996. Effects of burial by sand on seedling growth and survival in six tropical sand dune species from the Gulf of Mexico. Journal of Coastal Research 12(2): 406-419.

Maun, M.A. 1985. Population biology of Ammophila breviligulata and Calamovilfa longifolia on Lake Huron sand dunes. I. Habitat, growth form, reproduction, and establishment. Canadian Journal of Botany 63: 113-124.

Maun, M.A. 1994. Adaptations enhancing survival and establishment of seedlings on coastal dune systems. Vegetatio 111: 59-70.

Maun, M.A. 1998. Adaptations of plants to burial in coastal sand dunes. Canadian Journal of Botany 76: 713-738.

Maun, M.A. \& Lapierre, J. 1986. Effects of burial by sand on seed germination and seedling emergence of four species. American Journal of Botany 73(3): 450-455.

Meijden, E. Van Der \& Waals-Kooi, R.E. Van Der 1979. The population ecology of Senecio jacobaea in sand dune system. Journal of Ecology 67: 131-153.

Reitz, R. 1961. Vegetação da zona marítima de Santa Catarina. Sellowia 13: 17-111.

Santos, C.R. \& Arruda, V.L.V. 1995. Floração, predação de flores e frutificação de Ipomoea pes-caprae e I. imperati (Convolvulceae). Insula 24: 15-36.

Sykes, M.T. \& Wilson, J.B. 1990. An experimental investigation into the response of New Zealand sand dune species to different depths of burial by sand. Acta Botanica Neerlandica 39: 171-181.

Waite, S. 1984. Changes in the demography of Plantago coronopus at two coastal sites. Journal of Ecology 72: 809-826.

Wilson, D.E. 1977. Ecological observations on the tropical strand plants Ipomoea pes-caprae (L.) R. Br. (Convolvulaceae) and Canavalia maritima (Aubl.) Thou. (Fabaceae). Brenesia 10/11: 31-42. 